Original Article

\title{
Intra-observer reliability in three-dimensional kinematic analysis of sacroiliac joint mobility
}

\author{
Thiago Rebello da Veiga ${ }^{1)}$, André Custódio da Silva ${ }^{2)}$, Rodrigo Teixeira Gomes da Silva ${ }^{3)}$, \\ Sandro Luiz Machado Carvalho ${ }^{3)}$, Marco Orsini ${ }^{3)}$, Júlio Guilherme Silva ${ }^{3 *}$ \\ 1) Rehabilitation Science Master Program, Augusto Motta University Center, Brazil \\ 2) Biomechanics and Motor Behavior Program, Rio de Janeiro State University, Brazil \\ 3) Human Movement Analysis Lab, Augusto Motta University Center: Praça das Nações $N^{\circ} 34,3^{\circ}$ \\ andar, Bonsucesso, Rio de Janeiro, RJ, Brazil
}

\begin{abstract}
Purpose] Physical therapists, osteopathic practitioners, and chiropractors often perform manual tests to evaluate sacroiliac joint (SIJ) mobility. However, the available evidence demonstrates an absence of reliability in these tests and in investigations with kinematic analysis. The aim of this study was to verify the three-dimensional kinematic reliability in SIJ movement measurements. [Subjects] This cross-sectional study analyzed 24 healthy males, aged between 18 and 35 years. [Methods] Three-dimensional kinematic analysis was performed for measurements of posterior superior iliac displacement and greater trochanter (femur) displacement during hip flexion movement in an orthostatic position. The distance variations were measured from a reference point in 3 blocks. The intra-observer reliability was compared with the mean of three 3 blocks using the interclass correlation coefficient (ICC) and a 99\% significance level. [Results] The measurements indicated a strong correlation among blocks: ICC $=0.94$ for right side SIJ and ICC $=0.91$ for left side SIJ. The mean displacement between the reference points was $7.7 \mathrm{~mm}$ on the right side and $8.5 \mathrm{~mm}$ on the left side. [Conclusion] Our results indicate that three-dimensional kinematic analysis can be used for SIJ mobility analyses. New studies should be performed for subjects with SIJ dysfunction to verify the effectiveness of this method.

Key words: Sacroiliac joint, Reliability, Three-dimensional kinematic
\end{abstract}

(This article was submitted Sep 29, 2014, and was accepted Nov 28, 2014.)

\section{INTRODUCTION}

The sacroiliac joint (SIJ) plays an important role in the axial skeleton's load distribution for the lower limbs, because it is the transition point between the upper and lower body ${ }^{1-3)}$. The SIJ movement pattern is complex because its anatomical configuration allows displacement in 3 planes and axes in a combined manner ${ }^{4}$. However, the amplitude of this movement is restricted to approximately 1 to $4^{\circ}$ of rotation and 1 to $2 \mathrm{~mm}$ of translation ${ }^{5,6)}$. These values may vary with age, gender, and weight or during pregnancy, and this variation has been the subject of study for the last two decades.

The SIJ significantly contributes to different motor patterns of the trunk and lower limbs, and some of these patterns are highly complex, such as the marching movement. From a clinical point of view, the SIJ is a joint with considerable propensity for arthrokinematic motion alterations, and a small decrease in the range of motion (ROM) is likely

\section{*Corresponding author. Júlio Guilherme Silva (E-mail:} jglsilva@yahoo.com.br)

C2015 The Society of Physical Therapy Science. Published by IPEC Inc. This is an open-access article distributed under the terms of the Creative Commons Attribution Non-Commercial No Derivatives (by-ncnd) License $<$ http://creativecommons.org/licenses/by-nc-nd/3.0/> . to develop before important musculoskeletal dysfunctions occur $^{9,10)}$, such as back pain, hip pain, and pain radiating to the legs and inguinal region ${ }^{11-14)}$. In the clinical setting, diagnosing disorders of the SIJ by physical examination, especially with regard to mobility, is difficult due to low levels of test reliability ${ }^{1,9,15)}$. However, studies have highlighted the need for a combination of 3 or more provocative tests to confirm sacroiliac dysfunction ${ }^{1,10,13,16,17)}$. Szadek et al. ${ }^{13)}$ claimed that Gaenslen's Thigh and Thrust tests individually are more reliable in the detection of sacroiliac dysfunction; however, several provocative tests should be performed to obtain a more accurate diagnosis. In such cases, the degree of mobility of the joint is neglected and is considered only with the presence of SIJ pain.

Today, blockade by intra-articular injection of anesthetic is the gold standard method for the differential diagnosis of sacroiliac dysfunction from the symptomatological point of view $^{1,7,14,15,17)}$. However, substantial evidence is lacking regarding viable alternatives for evaluation and quantification of SIJ mobility, especially for applicability in clinical practice.

Among the existing experimental models for SIJ movement analysis, the most reliable method for the evaluation of mobility is radiostereometry guided by fluoroscopy with contrast administration ${ }^{1,6)}$.

However, this is an invasive method, the findings can be difficult to interpret, and it is very expensive. There is 
no noninvasive gold standard mobility test for the SIJ. As with the provocative tests, positional and mobility tests have been the subject of investigation, and the empirical evidence suggests poor reliability ${ }^{7,13)}$. Among the tests used for SIJ mobility assessment, the most widely used in clinical practice is the Gillet test. However, this test does not have sufficient reliability to be accepted as a good evaluation parameter $\left.{ }^{13}, 16,17\right)$. Based on this information, the present study aimed to determine the reliability of three-dimensional kinematics during hip flexion in an orthostatic position as a quantitative method of evaluating sacroiliac mobility.

\section{SUBJECTS AND METHODS}

This cross-sectional study analyzed 24 males between the ages of 18 and 25 years in the Laboratory of Human Movement Analysis at Augusto Motta University Center (LAMH / UNISUAM). The inclusion criteria were as follows: no history of spine or lower limb surgery, asymptomatic, no central or peripheral nervous system motor impairment, and a body mass index (BMI) between 18.10 and $24.90 \mathrm{~kg} / \mathrm{m}^{2}$. We excluded subjects with a real lower limb length discrepancy of more than $1 \mathrm{~cm}$ (confirmed by scanometry), patients presenting with pain for 6 months before the trial, and patients with allergic reactions to tape (for marker points). The subjects that did not complete the tests due to pain during the experiment were excluded from the studies. The subjects were invited to participate in this study, and after being accepted, they signed a consent form. The work was approved by the Ethics and Research Committee of UNISUAM (no. 119.785 / 2012).

A three-dimensional kinematic analysis system (Qualysis motion system, Qualisys AB, Gothenburg, Sweden) was used to analyze the movements of the subjects. The apparatus was composed of three infrared cameras arranged in a semicircle to record the movements of the reflective markers attached to the anatomical points of interest. The equipment was calibrated according to the manual on each day of sample collection, and the sampling frequency was $120 \mathrm{~Hz}$. The subjects were asked to wear only a pair of Lycra shorts. In the first stage, we measured the anthropometric data and performed five irritative manual tests (thigh thrust, Gaenslen's, spring, Patrick, and sacral thrust tests).

The goal of the first stage was to exclude subjects with SIJ dysfunction. (i.e., subjects with three or more positive test results were excluded). Next, reflective markers were fixed on the following anatomical points: posterior superior iliac spines and the higher trochanters and epicondyles of the femur.

The subjects then stood in a bipedal standing position against a support bar and performed 3 hip and knee push-ups with each lower limb, and the movement was recorded by the Qualisys system. This procedure was repeated 3 times.

The primary outcome measure was the displacement distance of the posterior superior iliac spine in relation to the higher contralateral trochanter during active hip flexion in the range of approximately $90^{\circ}$ in the standing position. The statistical analysis was performed using SPSS 20.0 for Windows ${ }^{\circledR}$. The characteristics and sociodemographic data of the subjects were tested for normality using the
Table 1. Descriptive variables of subject characteristics expressed as means and standard deviations

\begin{tabular}{lcc}
\hline \multicolumn{3}{l}{ Subject characteristics $(\mathrm{n}=24)$} \\
\hline & Average & Standard deviation \\
\hline Age (years) & 24.46 & \pm 4.36 \\
Weight $(\mathrm{kg})$ & 71.10 & \pm 7.91 \\
Height $(\mathrm{cm})$ & 174.92 & \pm 5.98 \\
BMI $\left(\mathrm{kg} / \mathrm{m}^{2}\right)$ & 23.20 & \pm 1.89 \\
\hline
\end{tabular}

Table 2. ICC of SIJ mobility

\begin{tabular}{lcc}
\hline & Right SIJ & Left SIJ \\
\hline Mean $(\mathrm{mm})$ & 7.70 & 8.50 \\
SD & 0.346 & 0.416 \\
ICC & $0.94^{*}$ & $0.91^{*}$ \\
\hline${ }^{*} \mathrm{p}<0.01$ & &
\end{tabular}

Kolmogorov-Smirnov test and are presented as averages (X) and standard deviations (SD). The intraclass correlation coefficient (ICC) was used to compare the values between the blocks of sacroiliac mobility tests for the right and left limb with a confidence interval of $99 \%(\mathrm{p}<0.01)$.

\section{RESULTS}

The sample consisted of 24 individuals, and no subjects were excluded due to SIJ dysfunction (Table 1). Thus, the goal established by the sample calculation was achieved with a confidence level of $95 \%$, a testing power of $80 \%$, and a margin error of $20 \%$.

Table 2 presents the mean, median, and standard deviations of the measurements and the ICC of the intra-observer reliability. The averages of the 3 blocks were compared for each hemi-body separately. The results demonstrated a strong correlation between the blocks (ICC $=0.94$ for the right SIJ and ICC $=0.91$ for the left SIJ). Both assessments were significant $(\mathrm{p}<0.01)$.

\section{DISCUSSION}

The assessment of SIJ mobility has great relevance in the clinical setting because SIJ mobility determines the appropriate therapeutic approach ${ }^{1,9,15)}$. The difficulties in detecting biomechanical alterations in the SIJ during a physical examination are obvious, and manual tests have insufficient reliability for this purpose ${ }^{10,13,15-17,19)}$. The literature indicates that the main limitation of these tests is the examiner's inexperience because the evaluated movements are extremely subtle $8,13,14)$

In this study, we found strong correlation coefficients for repeated measures of sacroiliac mobility. The threedimensional kinematics analysis was implemented as a tool to promote the enhancement of the measurement of motion replacing palpation used in manual testing ${ }^{10,13,14,20)}$. Our results agree with the literature regarding the use of 
laboratory equipment as a possible alternative method of increasing the analysis accuracy. The current devices have sufficient precision to measure displacements of only a few millimeters $^{20,21)}$.

Kinematic analysis is a method that has established validity and reliability in the literature for the evaluation of several human movement patterns ${ }^{22-24)}$. However, it has not been commonly used to measure SIJ movements. Webster, Wittwer, and Feller ${ }^{21)}$ compared different three-dimensional motion analysis systems and found excellent coefficients of repeatability and excellent levels of intra-examiner agreement (ICCs ranged from 0.92 to 0.99 ). Bussey et al. ${ }^{25}$ ) tested a kinematic analysis device that performs magnetic tracking of surface markers and reported results very similar to our results.

However, Bussey et al. ${ }^{25)}$ evaluated another movement pattern of the lower limbs because their purpose was to detect sacroiliac mobility differences between males and females. The studies performed by Ahia et al. ${ }^{26,27)}$ aimed to determine the validity of the process of setting markers at anatomical reference points because this step is crucial for obtaining the data. Strong correlation values were observed in the ICCs $(\geq 0.90)$ in studies with good methodological quality according to the inclusion criteria for systematic reviews established by the Quality Assessment of Diagnostic Accuracy Studies (QUADAS).

One of the greatest advantages in using video kinematics for the evaluation of movements (which were previously tested only by palpation) is the potential to extract reliable quantitative data on the range of motion, which cannot be achieved through the execution of conventional manual tests, which provide only qualitative data ${ }^{28,29)}$.

Studies conducted on cadavers with radiographic analysis systems and contrast administration report that the mobility of the SIJ varies from 1 to $4^{\circ}$ of rotation and 1 to $2 \mathrm{~mm}$ of translation ${ }^{5,6,8)}$. These results differ from the findings obtained in this study, where the average displacement value was $8 \mathrm{~mm}$. However, the values presented by the previous authors refer to the real mobility of the SIJ, and, in the present work, the distance variation between the posterior superior iliac spine (PSIS) and greater trochanter of the contralateral limb was estimated as an indirect estimate of SIJ mobility.

To establish an accurate means of evaluation and feasibility in physical therapy practice ${ }^{30-33)}$, our experiment mimicked the motor patterns already commonly used in evaluations through manual testing. Thus, the manual test findings can be enhanced without challenging clinical reasoning and interpretation inherent to the investigative essence of the test. Observation of the movement relationships between the anatomical reference points chosen not only provides information on the core mobility of the SIJ but also clarifies issues related to the biomechanical behavior of the entire lumbo-pelvic complex. Therefore, we analyzed the magnitude of the displacement between the reference points and did not analyze the individual structures through vector decomposition of their motion.

One of the limitations of the present study is that there is no gold standard methodology established for the noninvasive assessment of SIJ mobility ${ }^{18)}$. Thus, it was impossible for us to compare our findings with data from other studies, which would establish values related to the reliability of the method. Second, we did not investigate the inter-examiner reliability. Therefore, the need for further studies using the same methodology of analysis remains to gain a better understanding of the proposed method, especially when applied to symptomatic individuals. We conclude that threedimensional kinematic analysis is a good tool for the estimation of SIJ mobility.

According to our data, the measurements demonstrated a strong correlation among the blocks of estimated SIJ range of motion, which confirms the method's intra-observer reliability. However, new studies must also be performed, especially for subjects with SIJ dysfunction. Thus, it may be possible to consolidate the evaluation of SIJ mobility through a three-dimensional kinematic analysis.

\section{REFERENCES}

1) McGrath MC: Clinical considerations of sacroiliac joint anatomy: a review of function, motion and pain. Int J Osteopath Med, 2004, 7: 16-24. [CrossRef]

2) Vleeming A, Albert HB, Ostgaard HC, et al.: European guidelines for the diagnosis and treatment of pelvic girdle pain. Eur Spine J, 2008, 17: 794-819. [Medline] [CrossRef]

3) Grassi DO, de Souza MZ, Ferrareto SB, et al.: Immediate and lasting improvements in weight distribution seen in baropodometry following a high-velocity, low-amplitude thrust manipulation of the sacroiliac joint. Man Ther, 2011, 16: 495-500. [Medline] [CrossRef]

4) Robert R, Salaud C, Hamel O, et al.: Anatomie des douleurs de l'articulation sacro-iliaque. Rev Rhum Engl Ed, 2009, 76: 727-733. [CrossRef]

5) Harrison DE, Harrison DD, Troyanovich SJ: The sacroiliac joint: a review of anatomy and biomechanics with clinical implications. J Manipulative Physiol Ther, 1997, 20: 607-617. [Medline]

6) Sturesson B, Uden A, Vleeming A: A radiostereometric analysis of the movements of the sacroiliac joints in the reciprocal straddle position. Spine, 2000, 25: 214-217. [Medline] [CrossRef]

7) Laslett M: Evidence-based diagnosis and treatment of the painful sacroiliac joint. J Manual Manip Ther, 2008, 16: 142-152. [Medline] [CrossRef]

8) Nianbin H, Cunningham BW, Sponseller PD, et al.: Kinematic analysis of the sacroiliac junction: a comprehensive investigation using human cadaveric spines. Spine J, 2009, 9: 47.

9) Hancock MJ, Maher CG, Latimer J, et al.: Systematic review of tests to identify the disc, SIJ or facet joint as the source of low back pain. Eur Spine J, 2007, 16: 1539-1550, 50. [Medline] [CrossRef]

10) Kamali F, Shokri E: The effect of two manipulative therapy techniques and their outcome in patients with sacroiliac joint syndrome. J Bodyw Mov Ther, 2012, 16: 29-35. [Medline] [CrossRef]

11) Irwin RW, Watson T, Minick RP, et al.: Age, body mass index, and gende differences in sacroiliac joint pathology. Am J Phys Med Rehabil, 2007, 86: 37-44. [Medline] [CrossRef]

12) Buijs E, Visser L, Groen G: Sciatica and the sacroiliac joint: a forgotten concept. Br J Anaesth, 2007, 99: 713-716. [Medline] [CrossRef]

13) Szadek KM, van der Wurff P, van Tulder MW, et al.: Diagnostic validity of criteria for sacroiliac joint pain: a systematic review. J Pain, 2009, 10: 354-368. [Medline] [CrossRef]

14) McGinley JL, Baker R, Wolfe R, et al.: The reliability of three-dimensional kinematic gait measurements: a systematic review. Gait Posture, 2009, 29: 360-369. [Medline] [CrossRef]

15) Clavel AL: Sacroiliac joint dysfunction: from a simple pain in the butt to integrated care for complex low back pain. Tech Reg Anesth Pain Manage, 2011, 15: 40-50. [CrossRef]

16) van der Wurff P, Hagmeijer RH, Meyne W: Clinical tests of the sacroiliac joint. A systematic methodological review. Part 1: Reliability. Man Ther, 2000, 5: 30-36. [Medline] [CrossRef]

17) Stuber KJ: Specificity, sensitivity, and predictive values of clinical tests of the sacroiliac joint: a systematic review of the literature. J Can Chiropr Assoc, 2007, 51: 30-41. [Medline]

18) Cusi MF: Paradigm for assessment and treatment of SIJ mechanical dysfunction. J Bodyw Mov Ther, 2010, 14: 152-161. [Medline] [CrossRef]

19) McGrath MC: Composite sacroiliac joint pain provocation tests: a question of clinical Significance. Int J Osteopath Med, 2010, 13: 24-30. [CrossRef] 
20) Moeslund TB, Hilton A, Krüger V: Survey of advances in vision-based human motion capture and analysis. Comput Vis Image Underst, 2006, 104 90-126. [CrossRef]

21) Webster KE, Wittwer JE, Feller JA: Validity of the GAITRite walkway system for the measurement of averaged and individual step parameters of gait. Gait Posture, 2005, 22: 317-321. [Medline] [CrossRef]

22) Ford KR, Myer GD, Hewett TE: Reliability of landing 3D motion analysis: implications for longitudinal analyses. Med Sci Sports Exerc, 2007, 39: 2021-2028. [Medline] [CrossRef]

23) McGinley JL, Baker R, Wolfe R, et al.: The reliability of three-dimensional kinematic gait measurements: a systematic review. Gait Posture, 2009, 29: 360-369. [Medline] [CrossRef]

24) McDermott A, Bolger C, Keating L, et al.: Reliability of three-dimensiona gait analysis in cervical spondylotic myelopathy. Gait Posture, 2010, 32 552-558. [Medline] [CrossRef]

25) Bussey MD, Milosavljevic S, Bell ML: Sex differences in the pattern of innominate motion during passive hip abduction and external rotation. Man Ther, 2009, 14: 514-519. [Medline] [CrossRef]

26) Adhia DB, Bussey MD, Mani R, et al.: Inter-tester reliability of non-invasive technique for measurement of innominate motion. Man Ther, 2012, 17: 71-76. [Medline] [CrossRef]
27) Adhia DB, Bussey MD, Ribeiro DC, et al.: Validity and reliability of palpation-digitization for non-invasive kinematic measurement - a systematic review. Man Ther, 2013, 18: 26-34. [Medline] [CrossRef]

28) Ribeiro S, Schmidt AP, Wurff P: Disfunção sacroilíaca. Acta Ortop Bras, 2003, 11: 118-125. [CrossRef]

29) Huijbregts P: Sacroiliac joint dysfunction: evidence-based diagnosis. Orthop Div Rev, 2004, 8: 10-29.

30) Son JH, Park GD, Park HS: The effect of sacroiliac joint mobilization on pelvic deformation and the static balance ability of female university students with SI joint dysfunction. J Phys Ther Sci, 2014, 26: 845-848. [Medline] [CrossRef]

31) Yoo WG: Effects of individual strengthening exercises on subdivisions of the gluteus medius in a patient with sacroiliac joint pain. J Phys Ther Sci, 2014, 26: 1501-1502. [Medline] [CrossRef]

32) Cho HY, Kim EH, Kim J: Effects of the CORE exercise program on pain and active range of motion in patients with chronic low back pain. J Phys Ther Sci, 2014, 26: 1237-1240. [Medline] [CrossRef]

33) Ohtsuki K, Suzuki T: A comparison of the immediate changes in subjects with chronic lower back pain effected by lower back pain exercises and direct stretching of the tensor fasciae latae, the hamstring and the adductor magnus. J Phys Ther Sci, 2012, 24: 97-100. [CrossRef] 